\title{
Analyzing Enterprise Architecture in National Governments: The cases of Denmark and the Netherlands
}

\author{
Marijn Janssen \\ School of Technology, Policy and \\ Management \\ Delft University of Technology \\ Jaffalaan 5, NL-2600 GA, Delft \\ The Netherlands \\ Tel. +31 (15) 2781140 \\ Marijnj@tbm.tudelft.nl
}

\author{
Kristian Hjort-Madsen \\ National IT and Telecom Agency \& \\ IT-University of Copenhagen \\ Holsteinsgade 63 \\ 1260 Copenhagen \\ Denmark \\ Tel: + 45 (28) 582582 \\ khm@itst.dk
}

\begin{abstract}
National enterprise architectures (NEA) promise to fill the gap between policy and implementation. NEAs are embedded within an institutional environment consisting of active players capable of responding strategically and innovatively to architectural initiatives, which might complicate NEA adoption.

In this paper we analyze the efforts of two European national governments in developing enterprise architecture. Grounded in institutional theory and practice we develop an analytical framework and use this framework to analyze the efforts of two countries, Denmark and the Netherlands. Our framework and analysis draws the attention to the need to take a broader perspective on enterprise architecture, especially governance aspects determine the adoption and diffusion of NEA.
\end{abstract}

\section{Introduction}

Governments around the world increasingly recognize the significance of enterprise architectures as leading-edge practice to improve services and efficiencies [13][14]. As part of public modernization plans, governments seek to offer citizens and businesses seamless on-line service by improving horizontal and vertical relationships and linking independently developed processes and information systems. In each country this has resulted in a wealth of independent e-government projects, which often have limited coherence and remain largely uncoordinated (e.g. [6],[9]). Current efforts are focused on coordinating the projects and providing a framework functioning as an umbrella for explaining the relationships among the projects and managing change. These kinds of frameworks are often denoted as national enterprise architecture (NEA). In this view, public administration is seen as a collection of a large number of heterogeneous organizations having different business processes and information systems. NEAs are aimed at ensuring interoperability, avoiding duplication of efforts and enable government-wide reuse.

In Europe several countries have initiated NEA initiatives over the past years [14]. These initiatives have been developed independent of each other. The research described in this paper is aimed at deepening our understanding of NEA. We do this by analyzing and comparing the NEA efforts of two European countries, which are well advanced with the development of their NEA and have a similar political and institutional structure. Both countries can be considered locomotives for developing NEA in the EU.

This paper is structured as follows. In the following section we discuss related literature. In section three we develop our analytical framework. In section four we use the framework to analyze the NEA of Denmark and the Netherlands. In section five the two countries are then compared. Then, in section six, the findings are discussed, and finally, conclusions are drawn in section seven.

\section{Enterprise architectures in government}

Enterprise architecture (EA) lacks a universally accepted definition [18]. An EA identifies the main components of the enterprise, its information systems, the ways in which these components work together in order to achieve defined objectives and the way in which the systems support business processes [10]. EA has been characterized as a system of systems [10], as the "master plan" or "city plan" [18] that detail 
policies and standards for the design of infrastructure technologies, databases, and applications [3],[20]. Architecture aims at creating some kind of coherence and structure in a chaotic environment using systematic approaches [1]. The term "enterprise" refers to the scope of the architecture, dealing with the organization as a whole or, in case of NEA, dealing with multiple agencies rather than with a small part. Architecture consists of statements of how an enterprise wants to use IT, not on what and how information has to be made available. The strategy and institutional setting provide the contexts for the architectural design choices and decisions.

Enterprise architecture frameworks and models provide ways to deal with the complexity including work (who, where), function (how), information (what) and infrastructure (how to) [20]. EA is aimed at guiding decision-making. Ross [20] criticized enterprise frameworks for taking a technologist view. Frameworks do not highlight the role of institutions and capabilities critical to enabling the governance, adoption and diffusion of NEA.

Institutions are social structures that have attained a high degree of resilience [21]. Institutional theory attends to the deeper and more resilient aspects of social structure by considering the processes by which structures become established. Neoinstitutionalist view organizations not as passive pawns that can be changed by new management paradigms, but as active players capable of responding strategically and innovatively to new changes in their environment [21]. Political scientists often distinguish between organizations and institutions [5]. Whereas organizations reward effectiveness, efficiency, and control over production, institutional environments reward normative requirements of appropriateness and legitimacy and, in some cases, conformity to procedures, presentations, symbols, and rhetoric. Institutional environment facilitate or retard processes of technical and structural change, coordination, and dynamic adjustment [11]. It considers not only consensus and conformity but also conflict and change in social structures. In this respect institution both enable and constrain architectural reform and the adoption of enterprise architectures.

\section{Framework}

Our framework for comparing NEAs is aimed at a taking a broad view on NEA within the public administration. Inspired by neo-institutional theory, enterprise architecture literature and the experiences of the authors with enterprise architecture in practice, a framework for analyzing NEAs was developed.

Architecting public administration involves designing public administrations to reflect the political and public managers' decisions at a strategic level in operational activities and decisions. As such NEA promises to fills the gap between policy and implementation. NEAs are often initiated at the political levels and diffused using different governance mechanisms. An NEA is meaningless if it is not adopted and used by public agencies. Architecture models, principles and standards make up the content of a NEA. This resulted in the following aspects that need to be analyzed to understand NEA.

1. Policies, actors and structures: This aspect encompasses the environmental and political drivers for EA. The strategic objectives for architecture are provided by political actors and constrained by democratic structures;

2. Governance: Architectures evolve over time and consequently governance structures and mechanisms are important to guide and encourage desired behavior;

3. Architecture frameworks and methodologies: Architecting takes a resource-based view on public administration and use frameworks and planning process methodologies;

4. Architecture principles and standards: Architects uses standards, principles and guidelines for guiding implementation;

5. Implementations: The scope operate across multiple implementations among many agencies and disciplines;

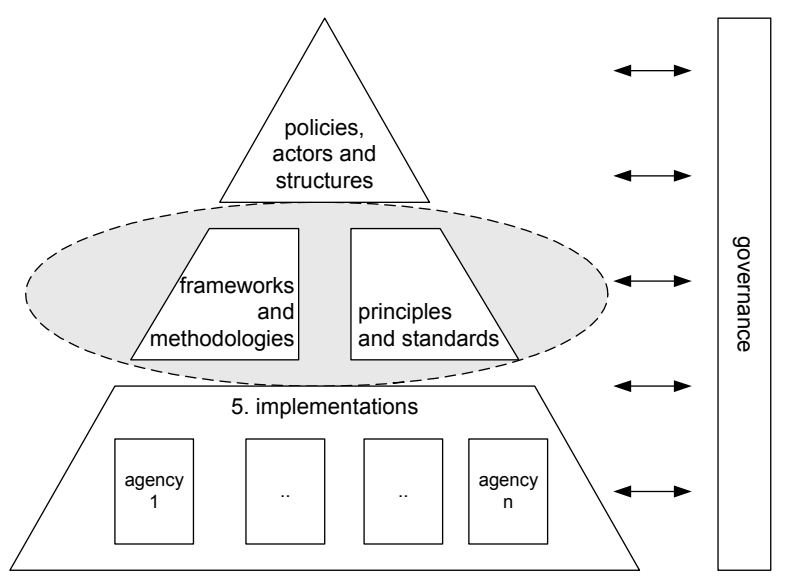

Figure 1: Framework for analyzing NEAs

Figure 1 shows the elements related to NEA. The grey circle shows the position where the architecting is performed; strategic decision and plans are translated into operational decisions and implementation using enterprise models, standards and architectural 
principles. In the following subsections we will further detail the elements of the framework.

\subsection{Policies, actors and structures}

The underlying premise for our analysis is that the institutional environment facilitates or retard processes of technical and structural change, coordination, and dynamic adjustment. Based on this institutional perspective, we expect that actors, structures and political vision affect the configurations of NEA programs. The national politics determine the level of ambition. The objectives of NEAs might vary considerably among countries. Similar, the number and types of agencies involved in enterprise architecture might be considerably different. NEAs might be guided and initiated at the political level or by public managers. In addition, governments might use Chief Information Officers (CIOs) to allocate responsibilities for adopting the NEA.

The structure of the public administration determines the way NEA programs can be designed, disseminated and adopted. The institutional structure needs mechanisms to govern NEA programs.

\subsection{Governance}

Governance represents the framework for decision rights and accountabilities to encourage desirable behavior in the use of IT resources [23]. Enterprises generally design three kinds of governance mechanisms: decision-making structures, alignment processes and formal communications [24].

Decision rights might be regulated and determined by laws. Agencies might adopt enterprise architectures on a voluntary basis, or have to comply with regulations and legislations. NEA might be initiated top-down or bottom-up. Alignment processes are techniques for securing widespread and effective involvement in governance decisions and their implementations. This includes the way the funding model of is organized. Formal communications concern two-way communication and good participation/collaboration relationships.

\subsection{Enterprise frameworks and methodology}

Zachman [24] introduced the concept of enterprise frameworks that provide multiple views on information systems. Frameworks are used for describing and understanding EA [10]. The NEA model(s) chosen determine what aspects can be captured at what level of abstraction. Spewak [22] added th planning process aspect to EA. As such NEA can take a framework or methodology oriented approach having various foci and levels of abstractions.

\subsection{Architectural principles and standards}

Architectural principles are statements that describe the constraints imposed upon the organization, and/or the decisions taken in support of realizing the business strategies. Principles restrict architectures and set the direction for the future. Architectural descriptions can form the basis for the implementation and transformation of existing structure into the desired architecture. Standards can be enforced at various levels, including standard business processes, standard technical building blocks and standardization of interfaces and interaction patterns.

\subsection{Implementation}

An EA can be viewed as the plan for the next infrastructure [20]. Implementation concerns the use and translation of the NEA models and principles to the situation of public agencies. This aspect provides indications for how (parts of) the NEA are adopted, used and updated. It also contains change support to enable the adoption and diffusion of the NEA

Implementation also includes the development and use of central facilities and infrastructures. Central facilities might be used by local agencies to support the development of their systems architecture. Also infrastructure might be provided by central government and readily available for use by local agencies.

\section{National government case studies}

We investigated the enterprise architecture efforts in Denmark and the Netherlands using our framework. Both countries have a capitalist production system and a parliamentary democracy. Furthermore, both Denmark and the Netherlands rank among the top- 10 countries when it comes to maturity in the survey of Accenture [1]. Consequently there NEA efforts might be comparable and the two countries might be able to learn from each other.

Denmark is a small country with 5,5 million citizens and the Netherlands has 16,3 million citizens. $83 \%$ of Danes and $90 \%$ of the Dutch have Internet access at home.

Table 1 shows a comparison of the demographic data of both countries based on data collected in 2005 . The Netherlands has three times the number of citizens of Denmark and also thee times the ICT budget of 
Denmark. The total number of employees working in government and related agencies is difficult to compare, as in the Netherlands there are many publicprivate partnerships and autonomous agencies that are not included in the statistics. In general the public sector in Denmark is a bit larger then in Netherlands, as might become clear from the public administration spending.

Table 1. Demographic data (www.cbs.nl; www.dst.dk)

\begin{tabular}{|c|c|c|}
\hline & Denmark & $\begin{array}{r}\text { the } \\
\text { Netherlands }\end{array}$ \\
\hline Citizens (millions) & 5,41 & 16,34 \\
\hline $\begin{array}{l}\text { Gross domestic product } \\
\text { (GDP) per capita in } \\
\text { Purchasing Power Standards } \\
(\text { PPS }),(\text { EU-25 }=100)\end{array}$ & 124.3 & 123.3 \\
\hline $\begin{array}{l}\text { Unemployment rates } \\
\text { represent unemployed } \\
\text { persons as a percentage of } \\
\text { the labour force }(\%)\end{array}$ & 4,8 & 4,7 \\
\hline $\begin{array}{l}\text { Public } \quad \text { administration } \\
\text { spending (\% of GDP) }\end{array}$ & 53.2 & 45,7 \\
\hline $\begin{array}{l}\text { Gross domestic expenditure } \\
\text { on R\&D (GERD) As a } \\
\text { percentage of GDP (of } \\
\text { businesses) }\end{array}$ & 2.56 & 1,76 \\
\hline $\begin{array}{l}\text { Number of public servants } \\
\text { (FTE) }\end{array}$ & 845.000 & 400.000 \\
\hline $\begin{array}{l}\text { Central government } \\
\text { employees (FTE) }\end{array}$ & 80.000 & 120.000 \\
\hline $\begin{array}{lll}\begin{array}{l}\text { Number } \\
\text { (number) }\end{array} & \text { of ministries } \\
\end{array}$ & 19 & 13 \\
\hline $\begin{array}{l}\text { Annual IT budget } \\
\text { government (Billion Euro's) }\end{array}$ & 0.8 & 2.3 \\
\hline $\begin{array}{l}\text { Percentage online services in } \\
\text { October } 2004(\%)\end{array}$ & 82 & 70 \\
\hline $\begin{array}{l}\text { Households with Internet } \\
\text { connectivity (\%) }\end{array}$ & 83 & 90 \\
\hline $\begin{array}{l}\text { Households with broadband } \\
\text { connectivity }(\%)\end{array}$ & 40 & 50 \\
\hline
\end{tabular}

Public reports about NEA were studied in both countries and we conducted in total 18 interviews with governmental representatives and users involved in enterprise architecture at the national level.

\subsection{Denmark}

Denmark is Europe's frontrunner in the use of NEA. The general challenges for the Danish egovernment project are the major restructuring of responsibilities across levels of government and improving cooperation between independent agencies. A recent OECD review of Denmark's e-government program [14] emphasized that, while the NEA and supporting standards and frameworks have been very well developed at the conceptual level, they are proving more difficult to translate into the actual standards and schemas required for implementation.

4.1.1 Policies, actors and structures, The main vision for Denmark's NEA efforts was formulated in a White Paper in 2003 [13]. The main recommendations of the white paper are that the public sector should take more active responsibility for its own enterprise architecture, a common enterprise architecture framework should be established for planning public sector IT systems and ensuring interoperability and there should be a concerted effort to shared knowledge among agencies.

The NEA white paper was published by the Coordinating Information Committee - a cross-public sector body with representatives from all levels of government. Top-level responsibility for e-government resides with the Danish Ministry of Finance (MF). However, the NEA work is performed in the Ministry of Science, Technology and Innovation (MVTU). MVTU also leads the national Enterprise Architecture Committee reporting to the Coordinating Information Committee and defines the policies for NEA.

EA has been an important but not a driving force in the development of e-government in Denmark. Different common infrastructure elements like common access management and a new infrastructure for business messages to the government (e.g. electronic invoices) have been initiated outside the NEA program. As a result there are different perceptions of what NEA is and what it is not. The cooperation for Danish Municipalities works closely with MVTU, but so far guidelines for the NEA at the municipal level have not been developed.

4.1.2 Governance, The Danish approach to NEA is driven by incentives, i.e. there are no legislation or regulations governing standards and principles for NEA development in government. The adoption of NEA is based on voluntarism and it is up to each public organization to assess their need for an NEA and decisions related to it. There are no financial incentives to adopt the NEA. NEA is primarily driven by the need for interoperability and adoption of best practices.

This decentralized governance model driven by incentives is also evident in our findings where individual municipalities described their EA planning efforts as relatively independently of other municipalities. Their relatively small size limits their 
financial and human resource capacities to adopt and use ICT strategically and there are therefore few common ICT systems and frameworks that have been developed by municipalities themselves.

MVTU works closely with other parts of government in the coordinating information committee and the enterprise architecture committee. MVTU hosts a yearly NEA conference, publishes EA guidelines, and on a national website (www.oio.dk) EA recommendations are posted and stakeholders can subscribe to a monthly newsletter. Furthermore, a NEA repository for architectural knowledge sharing and maturity assessments is currently in its beta version.

\subsubsection{Architecture frameworks and} methodologies, In 2003, the NEA white paper a highlevel process model was introduced. Since then a handbook on NEA implementation, also published by MVTU, has defined a generic architectural process for NEA. The basic NEA process model is illustrated in figure 2 below.

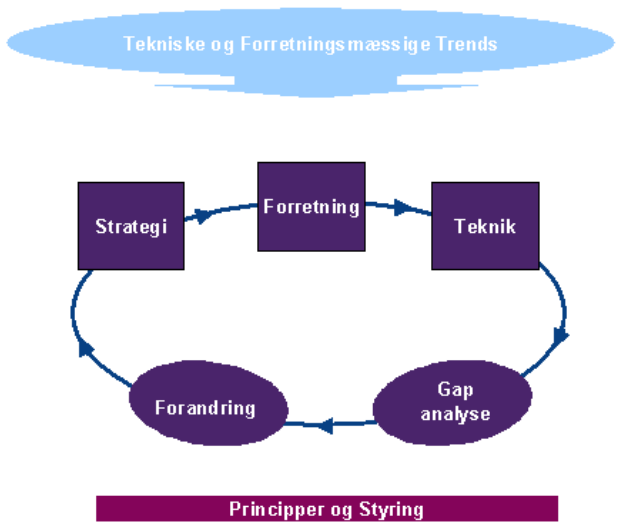

\section{Figure 2: The NEA process model of Denmark [12]}

The NEA model prescribed by MVTU is based on the Zachman framework (e.g. [24]), but it focuses more on the planning process as proposed by Spewak [22] than the artifacts within the different cells of the Zachman framework. The model is viewed as a starting point by MVTU for initiating the EA program.

\subsubsection{Architecture principles and standards, The} NEA process model deals with non-mandatory principles and the selection of standards. In the NEA white paper published in 2003 [13] five categories of principles were suggested: interoperability, security, openness, flexibility and scalability.
Although these principles are not mandated by, our interviewees indicated that they have had a large effect on the NEA development. One of the respondents described it: "We use the recommendations in the White Paper a lot... I know that everybody looks at these five principles every time they make requirements for a new IT-project and talks to vendors".

A national interoperability framework has been established to support standards decisions in NEA programs. MVTU is in charge of this interoperability framework and makes recommendations about 609 selected standards, specifications and technologies used in e-government solutions. As part of the framework a different decision support tools e.g. for multimedia standards are published dynamically. Again the recommendations are not mandated by regulations or legislation, the Danish approach is primarily based on incentives.

4.1.5 Implementations, As governance model is based on incentives rather than laws and regulations, the implementation of NEA in Danish public agencies is rather fragmented. Many of the NEA initiatives, like common access management, are based on ad-hoc decision processes and not a national to-be architectural vision. Furthermore, initiatives like the interoperability framework and a new initiative for public procurement are only loosely integrated with the proposed NEA models prescribed by MVTU.

At the decentralized level some agencies have very advanced NEA programs with strict EA policies for the organizational and technical standards and principles governing the IS development, while others have not even established a program. Service-Oriented architecture (SOA) has been promoted as the preferred architectural style for government [14] and many agencies are currently modernizing their ITinfrastructure based on SOA principles.

\subsection{The Netherlands}

The Netherlands was a frontrunner in the field of egovernment at the beginning of this century and although there are many examples of innovative projects, the current e-government efforts lag behind the ambitions [14]. In 2004 the Ministry of government reforms initiated a NEA. The aim of the NEA program is to reduce red tap, as calculations showed that cutting red tape will have positive longterm effects on economic growth, employment and income [15]. 
4.2.1 Policies, actors and structures, Within the existing laws and financial regulations of the Netherlands, the local governments enjoy a high degree of autonomy in making their own decisions. They have their own budgetary control and can make independent IT investment decisions. The local governments are hierarchically organized with varying degrees of coupling and autonomous coordination.

The NEA program was aimed at capitalizing the best practices. The basic idea is to stimulate many heterogeneous and similar projects at the decentral level. After a while a project might become successful and similar initiatives are not supported anymore and the project results become part of the NEA and disseminated as a best practice. The strategy is "grow many plans and harvest only one"[9].

4.2.2 Governance, The enterprise architecture developed at the national level is aimed at guiding the directions of other agencies. The policies and laws are focused on stimulating online-services provisioning, the reuse of data and the creation of a one-stop shop [14]. How this is realized (e.g. standards, shared services) is left to the organizations, except the use of vital record registries, which is determined by law.

There are a large number of centralized programs. They regularly held workshops, write reports and distribute newsletters to inform governmental agencies. There is no overall coordination, as a result, some interviewees indicated that they are sometimes overwhelmed by the large number of initiatives and do not understand the dependencies among all the programs.

The transformation process is completely left over to the local agencies. Various ministries have not allocated budget to create 'change support teams' that should help to implement parts of the application architecture. It is especially focused on stimulating the use of the infrastructure building blocks. One representative of a municipality stated that "Architecture should prescribe the use of standards and applications and all agencies should comply to that". The rational is that municipalities have huge problems with integrating their systems with other municipalities.

\subsubsection{Architecture frameworks and} methodologies, The NEA program is based on adopting one part of the Zachman model as shown in figure 3 . The architecture is driven by requirement for EU, Dutch government, businesses and citizens. On the vertical axis business, information and technical architecture are shown on the horizontal axis contains who? what? and how? questions. Control and maintenance and security are given special attention.

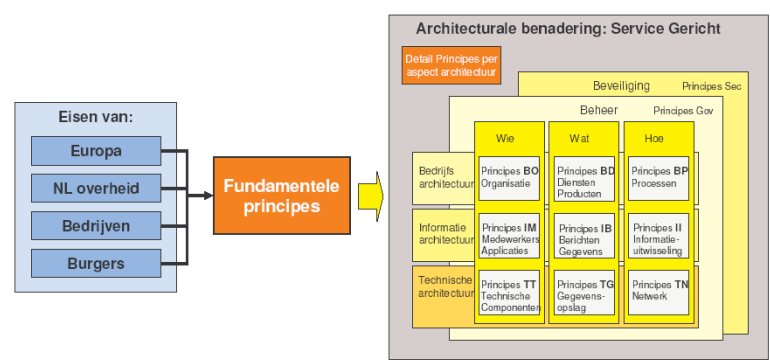

Figure 3: NEA framework of the Netherlands

The model is primarily used as a way to structure architecture principles and best practices. The webbased version contains hyperlinks to these principles and practices. The interviewees indicated that "the Zachman framework is too complex to support communication.... it is too abstract to capture our architectural problems".

4.2.4 Architecture principles and standards, The NEA contains over 160 principles [7]. However, some are overlapping and the principles also include policies like $60 \%$ of the services should be provided online [15]. The interviewees commented that the principles are rather at a high and abstract level, as an example was given the principles "one stop shop" (which is also a policy), "separate status and content data" (already known for decades) and 'make maximum use of vital records' (indeed as much information should be reused as possible). On the other hand they found it very useful that all principles are collected, maintained and disseminated by one department.

There are a number of standards, however, the organizations responsible for developing and maintaining these standards have no direct link to the NEA program. The program does refer to these standards and encourages the use of these standards. The interviewees representing municipalities found it very hard to find the right standards, "Isn't it annoying when you can't find a standard you expect or even better know to be out there?".

4.2.5 Implementations, The architecture efforts are fragmented and, except for documentation, there is no focal point [8]. Most of the initiatives are implemented after spotting the success of local agencies or at other countries. A complete picture is currently lacking, however, a program has been initiated to craft the relationships among projects.

There is a NEA at the central level, and several, 
relatively large, agencies have their own EA. Often these do not comply with the centralized EA. Moreover agencies are starting to implement new initiatives without considering the NEA. An oftenheard complaint is that "again the problems and unique characteristics of the local level are ignored", however, also was stated that "the local level is not as unique as we think we are. Collaboration, standards and sharing of systems should be compulsory" .It seems there are persons having a skeptic view on NEA, but also persons having a positive view. "The use of the NEA pictures, models and visualizations supports the discussions with our decision-makers. We can use it to explain the impact of decisions.... It enables us to speak the same language".

The NEA program has adopted the service-oriented architecture paradigm and the complete reference application architecture is SOA-oriented. The NEA program includes basic infrastructure building blocks, which are implemented by other programs of the ICTU.

\section{Cross-country comparison}

The NEA program in both countries consists of many interdependent projects resembling many similarities. This does not come as a surprise as the two countries have similar democratic systems, are comparable in size and NEA is developed to deal with similar problems. The readiness of the public sector is comparable as the public sector structure is similar. There are, however, also several differences. Table 2 depicts a systematic comparison using our framework.

The main concern of the Danish government is ensuring interoperability, whereas in the Netherlands the development of the NEA is largely driven by the need to reduce red tape. Both strategies are incremental strategies and try to deal with the existing organizations and installed systems. Denmark is a frontrunner in using architecture and encounters several early adapter problems. The NEA program was - and is - not well integrated with other e-government initiatives. In the Netherlands the NEA is primarily build on practices that are only integrated in the NEA after proven success. If for a certain area, no proven practices can be found, many small projects are stimulated, which should result in the creation of a new proven practice. This is largely a risk-avoiding strategy and takes a much longer time to develop. In some respect Denmark is used as a leadership for the Dutch NEA as several of the building blocks are based on best practices found in Denmark.

Table 2. Cross-country comparison of the NEA's of Denmark and the Netherlands

\begin{tabular}{|c|c|c|}
\hline & Denmark & the Netherlands \\
\hline $\begin{array}{l}\text { 1.Policies, actors } \\
\text { and structures }\end{array}$ & $\begin{array}{l}\text { The Ministry of Science, Technology and } \\
\text { Innovation drive Enterprise Architecture initiatives. } \\
\text { Strong collaboration with Danish Municipalities } \\
\text { and the Ministry of Finance. Focus on } \\
\text { interoperability }\end{array}$ & $\begin{array}{l}\text { Initiated by the Ministry of Government } \\
\text { Modernization and Innovation. Strong focus on } \\
\text { reducing the administrative burden for companies } \\
\text { and public agencies (red tape). }\end{array}$ \\
\hline 2.Governance & $\begin{array}{l}\text { The NEA governance model is based on incentives. } \\
\text { Agencies are free to design their own architecture. } \\
\text { No legislation or regulations dictate the NEA } \\
\text { adoption. }\end{array}$ & $\begin{array}{l}\text { The NEA program is centrally initiated and } \\
\text { coordinated. No mandatory use of NEA. } \\
\text { Agencies are free to design their own architecture. } \\
\text { Change support teams have been created to help } \\
\text { agencies to adopt the EA. }\end{array}$ \\
\hline $\begin{array}{l}\text { 3. Architecture } \\
\text { models }\end{array}$ & $\begin{array}{l}\text { A generic NEA model was published in a } 2003 \\
\text { White Paper on NEA and a } 2004 \text { Handbook outlines } \\
\text { the methodology. } \\
\text { The NEA model is based on the Zachman } \\
\text { framework, but is primarily focused on the planning } \\
\text { process dimension. }\end{array}$ & $\begin{array}{l}\text { A simplified version of the Zachman model is used } \\
\text { to structure the architectural principles. } \\
\text { The NEA program uses no architectural models. } \\
\text { At the local level public agencies have adopted a } \\
\text { variety of architecture models. }\end{array}$ \\
\hline $\begin{array}{l}\text { 4. Architecture } \\
\text { principles and } \\
\text { standards }\end{array}$ & $\begin{array}{l}\text { A national Interoperability Framework guides the } \\
\text { use of technical standards based on } \\
\text { recommendations (no clear integration with NEA). } \\
\text { The White Paper defines high-level principles for } \\
\text { NEA. }\end{array}$ & $\begin{array}{l}\text { A set of high-level principles and guidelines. Most } \\
\text { of the principles are derived using a bottom-up } \\
\text { approach. Setting standards is largely avoided. NEA } \\
\text { efforts are primarily consensus based. }\end{array}$ \\
\hline 5.Implementations & $\begin{array}{l}\text { Service-oriented architecture is the dominant } \\
\text { paradigm. } \\
\text { Development and implementation of standard } \\
\text { building blocks are adopted in an ad-hoc manner. }\end{array}$ & $\begin{array}{l}\text { Service-oriented architecture is the dominant } \\
\text { paradigm. Development and implementation of } \\
\text { standard building blocks is adopted. }\end{array}$ \\
\hline
\end{tabular}


Both countries are struggling to ensure that NEA becomes more than just a paper exercise. The local autonomy limits the take up and no formal CIOs are responsible for EA in any of the countries. In both countries this also means that the NEA must be comprehensive and understandable - something that both countries are struggling with. The Dutch NEA is consensus-based and conflict avoidance. It contains only elements where there is consensus among all actors, elements that might be subject of discussion are left out. Consequently, the enterprise architecture lags behind innovative projects and the added value is limited for the early adopters in the local governments. It is primarily of interest for public organizations in the backfield of e-government developments, which makes up the largest amount of agencies. As such this strategy is right for ensuring homogeneity among the late adopters, but does not match the high-ambition of the politicians.

In the Netherlands the present NEA efforts tend to be designed primarily to solve actual problems, whereas the longer term goal remain more abstract, such as gain large economic and social benefits, ensure accessible and usable by all. The Danish NEA takes a more integral view even though the overall coordination of initiatives is difficult. The decentralized governance model based on incentives offers public agencies no direct economic and/or immediate political incentives to establish EA programs and the adoption is therefore entirely based on the voluntary adoption of "best practice".

The development of architecture models is problematic in both countries. The Zachman framework is used as a starting point in both countries. However, it is criticized for capturing not the complete picture, being too abstract and not supporting communication. Both countries take a different route to using NEA. Denmark efforts are concentrated on the planning process dimension, whereas the Dutch NEA is primarily a set of principles and guidelines structured using a framework based on the Zachman model.

In both countries implementation is based on service-oriented architecture paradigm, where centrally defined building blocks can be reused among the different government domains. Despite the similarities the actual implementations vary considerably among the countries. This comes due to the fragmented adoption patters we observed and the lack of a centrally mandated EA strategy and strong leadership.

In conclusion, there are similarities and differences among the countries. Denmark can learn a lot from the Netherlands' approach to harvesting best practices in the NEA program and the strong focus on red tape reduction. The Netherlands can learn from the interoperability elements and the planning process focus on the Danish NEA. The most conspicuous similarities are that both countries do not have centrally enforced NEA models and that both countries are struggling with the governance and implementation of the national architecture. Architectural models are perceived as difficult, too abstract and consequently are only used to provide structure to the NEA efforts. The governance seem their main problem to advance NEA efforts. As such, the NEAs become a product of the institutional environment that they are infused into and the organizational negotiation at different levels of government.

\section{Discussion}

NEA planning and development efforts are huge and complex encompassing many projects and the involvement of many public agencies. In Denmark and the Netherlands we witness the influence of the politicians' ambition to reinvent government with EA. As we know from the public policy literature, public agencies are, however, not always able to implement all initiatives and influencing this vision by blocking actors [16]. Especially the autonomy of municipalities blocks several initiatives taken at the high level.

In both countries enterprise architecture is encoded into institutions through a socialization process. When internalized, the use of NEA transforms behavior. When the actor behaves according to the NEA, the institution is enacted. In the Netherlands and Denmark we found agencies, who enacted the NEA, but also agencies who resisted and rejected the NEA. Resistance might be based on rational elements, for example systems are different, or on non-rational elements, like the not-invented here syndrome. After some time, we expect that parts of the NEA become sediment and taken for-granted, while other might change and be updated. Then, the behavior of actors will be partly influenced by the NEA and the NEA will become institutionalized. Acting in accordance with the NEA is viewed as rational by those who share the way of thinking, however, the creation of a shared visions is problematic. "It was all a bit of a muddling through" stated a representative of the local level who was trying to implement the NEA in his agency.

In 2003 Denmark developed a generic NEA model and has a handbook outlining the methodology, including building blocks to support the efforts. The Dutch created a high level model. However, the Dutch architecture is mainly a collection of principles and guidelines supported by several implemented building 
blocks. There are standards available, however, the standardization efforts are not interrelated. For example standards for social security are developed independent of standards for citizens' data. Only in April 2006 the funding for creating change support teams has been allocated. The Dutch strategy taken is a risk-avoiding strategy, based on proven examples. Consequently there are hardly any project failures at the national level.

In Denmark the main concern is interoperability, which requires a holistic view on the public organizations. However, this requires a strong governance model - something that Denmark does not have. Many public managers have questioned EA as the right instrument for creating interoperability in government at large. The EA frameworks and models that we use in the public sector were built for private companies and have a limited scope, while egovernment is about a large set of organizations, including many autonomous agencies having various levels of readiness and different circumstances, governed by a democratic system and embedded in a certain institutional situation. Like the Netherlands, Denmark must work with the integration of different egovernment into the NEA if they want to succeed, and much more attention must be given to the actual implementation of the NEA.

For the Danish and Dutch public managers a huge challenge is to keep up with the many initiatives and improve their systems to reduce red tape. One interviewee stated "you may not think architecture is critical, but look at the chaos without it". About the questions about the performance the uncertainty dominates. As one interviewee stated "it is better to have any guidance than none at all'. Moreover although the building blocks are not suitable for all organization, several interviewees stated "the modules enables us to reduce development costs and ensure we can implement e-government requirements". The question remains whether EA is the right medicine for public organizations? Rigorous EA frameworks, vague definitions and organizational adoption are some of the largest challenges. Tomorrow's NEA programs in government must therefore encompass institutional dynamics as well as be agile in the application of interoperable e-government services.

One of our starting points is that a broader view on NEA should be taken. NEAs are intertwined with many other aspects and analyzing one aspect without considering the others is a too narrow view on NEA. Both countries are struggling to ensure that NEA becomes more than just a paper exercise. Therefore a broader look should be taken at NEA. NEA evaluation should also involve the governance aspects, including decision-making structures, alignment processes and formal communications, and the take-up of the NEA by studying the implementations. As one of the interviewees phrased it " $a$ NEA without governance mechanisms ensuring the adoption is like a restaurant without providing any food".

The advantage of our framework is it draws the attention to the need take a broader view on NEA than is usually taken by enterprise architects. The analysis framework offers a contextual understanding of the NEA efforts, which is closely related to the understanding of public managers and architects. The context of government is simply very different from the (private sector) context in which the general EA discipline was originally developed. The institutional perspective alerts us to the fact that government is likely to use IS differently than private firms would use it. Institutional theory offers insight by conceiving EA programs as having institutional elements of their own, while also being subject to institutional pressures from public organizations.

\section{Conclusions}

In this paper we developed a broader understanding of NEA by first developing a framework to analyze national enterprise architecture and then using this framework to analyze the NEA initiatives in Denmark and the Netherlands. Denmark kicked off NEA very early in 2003 and the Netherlands waited for EA to mature and has a risk-avoiding strategy. Denmark is a frontrunner and seems to be loosing a bit of its first mover momentum. Both countries studied here are increasingly using their NEA programs as instruments to govern the public-sector organizational network from an integrated strategy, business and technology perspective.

The Netherlands can learn from the use of NEA frameworks and models from Denmark, whereas Denmark can draw lessons from the governance in the Netherlands. Both countries are struggling with the governance of their NEA efforts, mainly due to the local autonomy of public agencies. Denmark has better collaboration and communication within levels of government, whereas the Netherlands have a better governance structure using funding control and portfolio management.

As the underlying premise for our analysis we took the institutional view, which predicts that, the configuration of NEA programs are significantly affected by actors, structures and political vision. Both case studies confirm this premise. In our case studies we found that NEA must be viewed broader than just a 
"city plan". In our framework we proposed that at least 5 elements should be considered 1) Policies, actors and structures, 2) Governance 3) Architecture model 4) Architecture principles and standards and 5) Implementations. Our analysis of the NEA confirms that there is a need for a broader perspective on NEA. The question is not only what the NEA is, but also how the NEA is used and governed over-time given the institutional setting. Analyzing NEAs should include the institutional environment, governance ts and the take-up of the NEA by studying implementations.

\section{References}

[1] Accenture. Leadership in Customer Service: New Expectations, New Experiences. [Web: www.accenture.com/Global/Research_and Insights/, last accessed June, 2006]

[2] F.J Armour,. and S.H Kaisler, "Enterprise Architectures: Agile transition and Implementation", IEEE IT Professional, Vol. 2, No. 6, 2001, pp. 30-37.

[3] S.B. Bernard, An introduction to Enterprise Architecture. Authorhouse, 2004.

[4] J.A. Carbone, IT Architecture Toolkit. Prentice HallPTR, Upper Saddle River, NJ, 2004.

[5] J. Fountain, Building the virtual state. Information technology and institutional change. Washington DC: Brookings Institution Press, 2001.

[6] K. Hjort-Madsen, "Enterprise Architecture Implementation and Management: A Case Study On Interoperability", Proceedings of the 39th Annual Hawaii International Conference on System Sciences, 2006.

[7] ICTU, Nederlands OverheidsReferentieArchitectuur. Samenhang en samenwerken binnen de elektronische overhead. ICT Programma Architectuur Elektronische overhead,

[http://elo.asp4all.nl/atlas/referentiearchitectuur/ Last accessed April, 2006] (in Dutch).

[8] M. Janssen and A. Cresswell, "An Enterprise Application Integration Methodology for EGovernment", Journal of Enterprise Information Management, Vol. 18, no. 5, 2005, pp. 531-547.

[9] M. Janssen and G. Kuk, "A Complex Adaptive System Perspective of Enterprise Architecture in Electronic Government", Hawaii International Conference on System Sciences (HICSS-39), January 5-7, Kauai, Hawaii, 2006.

[10] S.H. Kaisler, F. Armour and M. Valivullah, "Enterprise Architecting: Critical problems", Proceedings of the $38^{\text {th }}$ Hawaii International Conference on System sciences, 2005.
[11] J. L. King, V. Gurbaxani, K.L. Kraemer, F.W. McFarlan, K.S. Raman, and Yap, C. S. "Institutional Factors in Information Technology Innovation", Information Systems Research, vol. (5 no. 2, 1994, pp. 139-169.

[12] Ministry of Science, Technology and Innovation. Handbook on Enterprise Architecture [Web: www.oio.dk/arkitektur/publikationer/haandbog, last accessed June 2006] (in Danish).

[13] Ministry of Science, Technology and Innovation (2003). Whitepaper on Enterprise Architecture. [Web: www.oio.dk/arkitektur/english, last accessed June 2006].

[14] OECD. OECD peer review of e-government in Denmark. [www.oecd.org, last accessed June 2006]

[15] Pechtold, A. Resultaten van de onderzoeken naar administratieve lasten. Letter to the parliament of the Minister of Innovation, [ http://www.lastvandeoverheid.nl/LVDO/Web/Resultate $\underline{\mathrm{n} / \text { Pechtold+brengt+bureaucratie+voor+burgers }+\mathrm{in}+\text { kaar }}$ t/, last accessed January 2006] (in Dutch).

[16] J.L. Pressman and A. Wildavsky, Implementation How Great Expectations in Washington Are Dashed in Oakland. University of California Press, London 1984.

[17] V. Peristera, and K. Tarabanis, "Towards an enterprise architecture for public administration using a top-down approach", European Journal of Information Systems, vol. 9, 2000, pp. 252-260.

[18] Rohloff, M. "Enterprise architecture: Framework and methodology for the design of architecture in the large", European Conference on Information Systems, 2005.

[19] Maier, M.W. \& Rechtin, E. (2002). The art of System architecting. CRC press Boca Raton, Florida

[20] J Ross, "Creating a strategic IT architecture competency: Learning in stages", MISQ Quarterly Executive, vol. 2, no. 1, 2003, pp. 31-43.

[21] W.R. Scott Institutions and Organizations. Thousand Oaks, CA, Sage, 1995.

[22] S.H. Spewak, Enterprise Architecture Planning. New York: John Wiley \& Sons 1992.

[23] P. Weill “Don't Just Lead, Govern: How best Performing Organizations Govern IT", MIS Quarterly Executive, Vol. 3, no. 1, 2004, pp. 1-17.

[24] P. Weill and J. Ross "A matrixed approach to designing IT governance", MIT Sloan Management Review, 46, 2, 2005, pp. 26-34.

[25] J.A. Zachman, "A Framework for Information Systems Architecture", IBM Systems Journal, Vol. 26, No. 3, 1987, pp. 276-292. 